\title{
Onchocerca Flexuosa. sp. (Nematoda: Filarioidea) in Japanese Wild Sika Deer (Cervus Nippon): Pathological and Molecular Identification of Intradermal Worms
}

Hoda Abd elatieff

Damanhour VET MED UNI

Eman Bazaa

Menofya UNIV

Shahinaz Hussin

Anima health research institute

Ituto Yamamoto

Animal heallth institute Japan

Tokuma Yanai

Gifu UNIV

Abdelrhman Abou Rawash ( $\square$ rawashaa@yahoo.com )

Damanhour UNI

\section{Research Article}

Keywords: Deer, histopathology, Japan, Onchocerca flexuosa, sequencing analysis.

Posted Date: June 7th, 2021

DOI: https://doi.org/10.21203/rs.3.rs-469044/v1

License: (c) (i) This work is licensed under a Creative Commons Attribution 4.0 International License.

Read Full License 


\section{Abstract}

More than thirty species of the genus Onchocerca (Nematoda; Filarioidea) were responsible for onchocercosis (a vector-borne parasitic disease) of wild and domestic ungulates. "Between 2016 and 2017", the presence of Onchocerca flexuosa (Wedl, 1856) was detected and investigated in 17 Japanese Sika deer (Cervus nippon) captured in Gifu and Shiga Prefectures, Japan. The worms were found within characteristics subcutaneous nodules dispersed in different regions of the body of all 17 deer. The all collected nodules were examined stereo-microscopically. The parasites were extracted from the nodules and identified through morphological and histopathological examinations. Molecular identification through sequencing of the following genes; internal transcribed spacer subunit 2 (ITS2)-28S ribosomal RNA (28S rRNA), cytochrome $c$ oxidase subunit 1 ( $\operatorname{cox} 1)$ and mitochondrially encoded NADH dehydrogenase subunit 2 (NAD2) were performed. The histopathological, molecular and phylogenetic analysis demonstrated that, the filarial nematode isolated from Gifu and Shiga Prefectures in Japan is 0 . flexuosa. This is the first report about presence of $O$. flexuosa in Japanese Sika deer (Cervus nippon) in Gifu and Shiga Prefectures.

\section{Introduction}

Various species of animals either domesticated (cattle, camels, and horses) or wildlife (deer, serows, and boar), can be infected by various species of Onchocerca all over the world. The parasites result in characteristic lesions in joints with muscular inflammation and lameness in ungulates [1]. Onchocerciasis is an established disease caused by filarial worms, which are transmitted by arthropods. Onchocerciasis, caused by 0 . volvulus, has been reported in Africa and Central/South America [2] resulted in a serious diseases as river blindness, which reported in different parts of the world [3].

Human infection was described in Europe caused by 0 . jakutensis which is a red deer origin [4]. Several clinical human cases, have been recorded worldwide which transmitted to human from animals: Among these cases, eleven were in Japan [5, 6]. Onchocerca flexuosa (Wedl, 1856) is a filarioid nematode (Spirurida: Onchocercidae), whose primary host is the European red deer (Cervus elaphus) [7]. The adult worms live inside subcutaneous connective tissue free or within firm fibrous connective tissue nodules. The nodules are heavily infiltrated by different types of inflammatory cells surrounding the coiled worms. The microfilariae are located near or far from the adult worms [8].

Routine diagnosis is mostly based upon microscopic examination to determine the morphology of the adult worm and its microfilaria. However, Giemsa staining cannot differentiate between the most related species [9]. Definitive diagnosis and control of such parasites are of great health concern, and specific molecular data will help scientists discriminate between closely related species and will also provide new drug target sites unique to the Onchocerca species.

A major strength of molecular identification depending up on specific DNA barcode, as it is allows correlation of any small part of parasites/organism to a single molecular entity (Molecular Operational 
Taxonomic Unit, MOTU) [10], and taxonomy skilled personnel does not necessary required in the molecular data analysis. cox 1 gene sequences and several others mitochondrial markers genes are widely used for DNA barcoding of metazoans $[11,12]$.

In the present study, we describe the morphological, pathological and molecular characteristics of worms of a novel Onchocerca species present inside subcutaneous nodules in the skin of a Wild Sika Deer (Cervus Nippon) in Gifu and Shiga Prefectures in Japan. The molecular diagnosis based on molecular identification of 3 genes; internal transcribed spacer subunit 2 (ITS2)-28S ribosomal RNA (28S rRNA), cytochrome $\mathrm{C}$ oxidase subunit 1 (cox1), and NADH dehydrogenase subunit 2 (NAD2).

\section{Material And Methods}

\section{Sample collection}

"Between 2016 and 2017" 17 wild Japanese deer from Gifu and Shiga Prefectures were captured by wildlife conservation authorities. These deer presented yellowish subcutaneous nodules in various parts of the body. The wild deers were slaughtered by licensed hunters in accordance with the policies of the Ministry of the Environment, Japan. The carcasses were refrigerated and transferred under cool conditions to the Laboratory of Veterinary Pathology, Faculty of Applied Biological Sciences, Gifu University, Japan. Five subcutaneous nodules from each deer were properly collected, cooled by ice wrapping and the collected nodules were all examined using a stereomicroscope. Parasites were detected in all the examined subcutaneous connective tissues nodules. Worms were removed with a pair of small forcipes, and saline was used for ease in detaching. The collected worms was then morphologically examined, Onchocerca nematodes were suspected to be the infective parasite based on the morphological features $[13,14]$. The worms collected from each nodule, rinsed in normal saline, and stored in $70 \%$ ethyl alcohol and used for parasitological and molecular identification. About $50 \%$ of the worms were used for parasitological identification and the rest of the worms were maintained at $-20^{\circ} \mathrm{C}$ until used for DNA extraction and PCR analysis.

Animals used in this study were also reviewed and handled according to code of ethics of Research and Animal Resources Committee, Faculty of Applied biological science, Gifu University, Japan, approved by Gifu university animal experiment committee.

\section{Histopathological examination}

Tissue specimens of subcutaneous nodules collected from the infected deer were fixed in 10\% neutral buffered formalin for histopathological examination. Fixed specimens were routinely processed through dehydration in ascending grades of ethanol, cleaned in xylene, and embedded in paraffin. Paraffin sections were obtained and stained with hematoxylin and eosin (H\&E) for histopathological examinations.

\section{DNA extraction}


Total DNA extractions from worm nodules were performed using the AllPrep® DNA/RNA Mini kit and DNeasy Blood \& Tissue Kit (Qiagen, Hilden Germany) according to the manufacturer's instructions.

PCR amplification: Each DNA extract was used as a template for PCR amplification using the specific filarial primers C01F3-C01R3 and ND2F1-ND2R1 [15]. In addition, parts of the nuclear ribosomal gene repeat were also amplified. The ITS2 region (with short portions of the flanking $5.8 S$ and $28 S$ genes) was amplified using previously published primers [16]. The PCR technique was performed in a $50-\mu l$ volume containing $4 \mu \mathrm{l}$ of DNA, $4 \mu \mathrm{l}$ of dNTP, $1 \mu \mathrm{l}(10 \mu \mathrm{Mol})$ of each forward and reverse primers, $5 \mu \mathrm{l} 10 \times$ Ex Taq buffer, $0.25 \mu \mathrm{l}$ Ex Taq polymerase (Takara, Kyoto, Japan), and $34.75 \mu \mathrm{l}$ distilled water. The PCR cycle for NAD2 and cox 1 genes was as follows: denaturation at $94^{\circ} \mathrm{C}$ for $3 \mathrm{~min} ; 30-35$ cycles of $30 \mathrm{sec}$ at $94^{\circ} \mathrm{C} ; 30$ s at $50^{\circ} \mathrm{C}$, and $1 \mathrm{~min}$ at $72^{\circ} \mathrm{C}$; followed by a final extension period of $5 \mathrm{~min}$ at $72^{\circ} \mathrm{C}$. PCR cycle for the ITS2 region (with short portions of the flanking $5.8 \mathrm{~S}$ and $28 \mathrm{~S}$ genes) was as follows: denaturation at $94^{\circ} \mathrm{C}$ for $5 \mathrm{~min} ; 35-40$ cycles of $94^{\circ} \mathrm{C}$ for $45 \mathrm{sec}, 58^{\circ} \mathrm{C}$ for $45 \mathrm{sec}$, and $72^{\circ} \mathrm{C}$ for $90 \mathrm{sec}$; followed by a final extension period at $72^{\circ} \mathrm{C}$ for $7 \mathrm{~min}$.

All PCRs were performed using the Takara Thermal cycler, Japan. PCR products were visualized and photographed in a $0.75-1 \%$ agarose gel containing $0.5 \mathrm{mg} / \mathrm{ml}$ ethidium bromide on a Gel Documentation System.

\section{DNA Sequencing, sequence alignment, and phylogenic analysis}

PCR amplicons were purified and prepared for sequencing using the QIA quick gel extraction kits ${ }^{\circledR}$ according to the manufacturer's instructions. The purified PCR products of all $O$. flexuosa positive samples were sequenced using the AB3500XL Genetic analyzer (Applied Biosystems, HITACHI, Japan) at the genome center of Gifu University, Japan using gene-specific primers.

The obtained nucleotide sequences of ITS2-28S rRNA, cox1, NAD2 and the deduced amino acid sequences of $O$. flexuosa were edited using the Sequence Scanner Software 2 program (http://www.appliedbiosystems.com). Primer sequences were omitted prior to phylogenetic analysis; the edited sequences were computationally compared with those of other filarial reference sequences for determining the homology and were subjected to phylogenetic analyses using the MEGA 7software (www.megasoftware.net/).

The phylogenetic trees were generated using the neighbor-joining ( $\mathrm{N}-\mathrm{J})$ tree method, and the reliability of internal branches was assessed by 1000 bootstrap replications $[17,18]$. The reference sequences of filarial genes were retrieved from the GenBank database, and their accession numbers are listed in (Table. 2).

\section{Results}

\section{Gross, morphological and histopathological results:}


Round, flat, ovoid or irregular nodules containing Onchocerca were found in subcutaneous tissues of the back, abdomen and flanks of examined deer either in isolated or fused form, giving the appearance of lobulated nodules (cauliflower growth). They were solid and hard, and often surrounded by thick fibrous connective tissue. Microscope-aided gross and parasitological examination of all collected subcutaneous nodules revealed presence of very thin, long, nematodes identified as filarial worms. 0 . flexuosa (Wedl 1956) (Order: Spirurida; Family: Onchocercidae, subfamily: Onchocercinae; Genus: Onchocerca). The living worms were transparent and opalescent, yellowish-white filarioids. The Esophagus is divided into anterior muscular part and slightly longer posterior glandular part. The length of the females was much longer (about $80 \mathrm{~mm}$ ) than the males (about $60 \mathrm{~mm}$ ). The female worms had a rounded anterior ends and its widest diameter was approximately $170-280 \mu \mathrm{m}$. The female cuticle was approximately $9 \mu \mathrm{m}$ thick with external delicate transverse cuticular ridges with small protuberances (Fig. 1A). The males had a distinctive coiled posterior end with caudal alae and reduced number of post-cloacal caudal papillae with two unequal spicules (the left one is longer). The right spicule structure has a prominently dorsal hook. The transverse ridges were $4 \mu \mathrm{m}$ apart at mid-body and tapering toward both ends.

Histopathological features of H\&E stained sections are illustrated in (Fig. 1B, C, \& D). The subcutaneous nodules exhibited multiple compartments or cavities containing numerous numbers of nematode sectioned at various orientations surrounded by fibrosing granulomatous tissue. Most of the nodules were inhabited by several females, with or without microfilariae, and fewer male worms lying in small cavities (Fig. 1B). The nematode body was formed of an outer layer of eosinophilic cuticle and a thick muscle layer. In the pseudocoelom of some worms, two engorged uteri and small-sized intestine were observed. Many developing microfilariae were observed in the uterine cavity (Fig. 1C). Eosinophil, lymphocyte, and plasma cell infiltration was observed in the fibrous nodules around the worms exhibiting strong fibroplasias leading to the formation of a parasitic granuloma (Fig. 1C, D). Amorphous eosinophilic material (Splendore-Hoeppli reaction) was observed around some female worms (Fig. 1B). Degenerated worms surrounded by granulomatous reaction consisting of remnants of worms, cell debris, eosinophils, macrophages, lymphocytes, and giant cells with a thick peripheral fibrous layer were frequently observed (Fig. 1D).

\section{Detection of 0 . flexuosa by PCR}

All collected subcutaneous nodules representing the 17 deer under investigation tested positive for cox 1 , ITS2-28S rRNA, and NAD2 genes segments by conventional PCR. The PCR amplicons from Onchocerca worms yielded around $600 \mathrm{bp}$ for ITS2-28S rRNA, and $1000 \mathrm{bp}$ for both cox1 and NAD2 (Supplementary Fig. 1). The PCR products were further sequenced for alignment with the reference filarial strains available on gene bank data base, and homology analyses as well as generation of phylogenetic tree were performed.

\section{Homology analysis of nucleotide and deduced amino acid sequences}

Homology analysis of the nucleotide sequences of the three filarial nematode genes cox 1 , ITS2-28S rRNA, and NAD2 as well as the deduced amino acid sequences of cox 1 , and NAD2 genes segments 
showed variable identity with the genes of different Onchocerca species available on the gene bank (Tables 2, 3, 4 and 5).

Alignment analysis of the nucleotide and amino acid sequences of $O$. flexuosa of our isolates and other published filarial worms was done. The results of alignment analysis of the nucleotide sequences of $O$. flexuosa of our isolates revealed presence of variation (mutations, insertions, and/or deletions) at several positions. Some of these nucleotide mutations were transcribed, resulting in subsequent mutation of the deduced amino acids, whereas others were silent nucleotide mutations. The nucleotide sequences of ITS2-28S rRNA gene segments from examined deer showed that the DNA fragment exhibited highest similarities with the sequences of some Onchocerca species (O. gibsoni, O. ochengi, $O$. volvulus, and $O$. gutturosa); data for which is available in GenBank.

The obtained nucleotide sequences of $\operatorname{cox} 1$ of the 0 . flexuosa isolate were compared with those of other 19 reference filarial strains. The results displayed regularity in variation at several positions as shown in (Supplementary Fig. 2). On the same side, the alignment analysis of the obtained nucleotide sequences of ITS2-28S rRNA with other reference filarial strains revealed presence of variation at several positions (Supplementary Fig. 3). In addition, the obtained nucleotide sequences of NAD2 of the 0 . flexuosa isolate were compared with those of other reported filarial strains. The results displayed regularity in the mutations at positions (Supplementary Fig. 4).

We compared the nucleotide sequences of Cox1, ITS2-28S rRNA and NAD2 genes sequences of Cox1 and ITS2-28S rRNA genes of our samples from captured deer with those of all Onchocerca species available in GenBank. Cox 1 sequence of this study showed high identity $(94 \%)$ with 0 . flexuosa isolated from Miyazaki Prefecture in Japan and from USA red deer isolates. It also showed $90-91 \%$ identity with human $O$. volvulus isolate obtained from Brazil, cattle $O$. ochengi isolate obtained from Cameroon, $O$. ochengi obtained from Miyazaki Prefecture Japan, The novel sequences obtained in the present study also exhibited reduced identity $(89.37 \%-89.68 \%, 91.78 \%)$ with Onchocerca dewittei japonica and Onchocerca skrjabini respectively using ITS2_28S sequence, and (87-89\%) with human filarial worms (Wuchereria bancrofti, Brugia timori, B. malayi, and B. pahangi) detected by using NAD2 sequence.

As shown in Table (3), p-distances in nucleotide sequences of cox 1 were $0-0.044$ for intra-species and 0.038-0.051 for inter-species of Onchocerca. Similarly the results of p-distances in nucleotide sequences of ITS2-28S rRNA and NAD2 genes were showed in tables $(3,4)$ and (supplementary tables 1.2 and 3 ).

\section{Phylogenetic analyses}

Phylogenetic trees for Onchocerca spp were constructed using the NJ and ML methods for the nucleotide sequences of cox1, NAD2, and ITS2-28S rRNA genes (Figs. 2, 3, and 4).

\section{ITS2-28S rRNA region}

In the same scene, the phylogenetic tree generated based upon the ITS2-28S rRNA region as shown in

(Fig. 2), revealed grouping of the onchocerca spp into two clades, clade 1 divided into two subclades. The 
first subclade included $O$. gutturosa and $O$. linealis. The one second containing $O$. volvulus (four leaves), 0 . ochengi from Porugal and Cameron. Also, give a relation with 0 . gibsoni. Clade 2 included 0 . flexuosa from Japan.

\section{Cox1 gene}

The phylogenetic tree generated based upon cox1 gene sequences as shown in (Fig. 3), showed that, the filarial species were distributed in two main clades. The first clade included three subclades the first one include $O$. flexuosa of different countries and districts (Japan, Miyazaki Prefecture and USA). The second subclade including $O$. ochengi isolated from Cameron and Miyazaki Prefecture. Also, related to $O$. volvulus (three leaves). The third subclade related to $D$. repens (four leaves). Clade II make a relation with W. bancrofti and Brugia sp.

\section{NAD2 region}

Similar to the phylogenetic tree generated based upon the Cox1 region; the phylogenetic tree of NAD2 region revealed presence of two clades. Clade I was divided into two subcldes. First subclade included only 0 . flexuosa species. Second Subclade included 0 . volvulus (three leaves), O. ochengi (four leaves) and give a relation with Loa loa. Clade II showing the relation with Dirofilaria species (Fig. 4).

The results clearly identified that Onchocerca species is the cause of parasitic nodules in the deer under investigation in the present study. As shown in (Table 2, 3, and 4), p-distances in nucleotide sequences of cox 1 were $0-0.018$ for intra-species and (0.017-0.051, 0.017-0.117 for inter-species of Onchocerca. In the same scene, our phylogenetic analysis based upon cox1, NAD2 and ITS2-28S rRNA genes indicated a close affinity between the present isolate of 0 . flexuosa and the previously isolated 0 . flexuosa, $O$. skrjabini, and O. eberhardi, isolated from Sika deer or serows in Japan. In contrast, Onchocerca flexuosa was distant from O. takaokain. sp and O. dewittei japonica, as shown in (Figs. 2 -4).

\section{Discussion}

Filariasis, and anthroponotic onchocerciasis have been reported worldwide and have caused problems either in animals or humans [5, 19], as many cases of zoonotic onchocercosis are reported [20]. Anthroponotic onchocerciasis has also been documented in Africa and Central/South America and has resulted in visual impediments in the affected individuals [6, 21].

In the current study, parasitic nodules in the form of yellowish subcutaneous nodules in various parts of the body have been observed in Japanese Sika deer (Cervus nippon) captured from Gifu and Shiga Prefectures in Japan. These findings are in agreement with the previously reported onchocerciasis in red deer (Cervus elaphus) in Switzerland [20]. The morphology of the present filarioids have the main characteristics of the genus Onchocerca that given by Bain [22] i.e. females have a thickened cuticle with transverse annular ridges on their surface and weakly developed muscular layer. 
Histopathological and the measurements analyzed, matched with those given in the description of $O$. flexuosa, carried out by earlier investigators $[7,8,23]$. The detected long female of 0 . flexuosa is identical to the female of 0 . jakutensis discovered by Bosch et al [20] from the Swiss red deer. Chronic parasitism in the form of multiple granulations around the worm and marked leukocytic cell infiltration of eosinophils, lymphocytes, macrophages, and plasma cells were observed and these granulomata were found mainly around female worms. Presences of many degenerated worms within several cavities in the nodules are an indication of a strong immunological response against $O$. flexuosa [8, 24]. Female worms were found more frequently in the nodules than males, they were embedded in the nodular fibrous tissue, and most of them were usually immobile due to an early degenerative alteration of their muscles. In contrast, mobility activity of males is higher than females as they can migrate subcutaneously leaving the nodules. Similar conclusions have been reached before $[8,25,26]$.

The presence of rivers and mountain streams enhance the vectors survival; resulting in high prevalence and intensity $[8,25,26]$. Both temperature and moisture are the most important environmental changes for all organisms. So, the ecology and the epidemiology of $O$. flexuosa are differing according the location. The prevalence of $O$. flexuosa in Sika deer was unknown in the Japan especially in the above mentioned examined regions. Prevalence of Onchocerca spp in wild and domesticated animals had previously appeared to be restricted to central and eastern Japan in Myazaki city (unpublished manuscript, gene bank reference number at https://www.ncbi.nlm.nih.gov/nuccore/AP017692.1), perhaps because these were the only areas where they had been studied. To the best of our knowledge, this is the first record of $O$. flexuosa in that area, as there is only one record of 0 . flexuosa from Myazaki/Japan in the GenBank.

In the present study, in order to confirm the molecular identity of $O$. flexuosa and to investigate its phylogenetic position, we compared the nucleotide sequences of cox1, NAD2 and ITS2-28S rRNA with those of all Onchocerca species available in GenBank. The nucleotide sequence of cox 1 in our samples of $O$. flexuosa was identical to other $O$. flexuosa isolated from Japan and was similar $(0.2 \%$ nucleotide differences) to $O$. skrjabini $O$. boehmi and $O$. lupi. The present isolate of $O$. flexuosa differed from $O$. dewittei japonica and 0 . takaokain. sp with differences of 4.7-4.5\% respectively in the nucleotide sequences of cox1. Sequence analyses of the ITS2-28S rRNA gene of 0 . flexuosa revealed a $5.8-7.4 \%$ difference compared with the nucleotide sequences of $O$. dewittei japonica and a $4.8-8.5 \%$ difference compared with that of other congeners. Similarly, the ND2 sequence analysis revealed a $5.8-7.4 \%$ nucleotide sequences difference compared with that of 0 . dewittei japonica and a $4.8-8.5 \%$ difference compared with that of other congeners.

P-distances in nucleotide sequences of examined genes as mentioned in the results and our phylogenetic analysis based upon cox1, NAD2 and ITS2-28S rRNA genes indicated a close affinity between the present isolate of $O$. flexuosa and the previously isolated $O$. flexuosa, 0 . skrjabini, and $O$. eberhardi, isolated from Sika deer or serows in Japan. In contrast, $O$. flexuosa was distant from $O$. takaokai $\mathrm{n}$. sp and $O$. dewittei japonica. Moreover, our results confirmed the previous reports $[27,28]$, indicated that the phylogeny of the family Onchocercidae based on the previously mentioned genes sequences plays a vital 
role in the classification of filarial worms along with the classification based upon morphological characters.

In a previous studies, DNA analysis and barcoding based on cox 1 and other mitochondrial genes was considered a reliable method for species identification of filarioid nematodes, with a high coherence with classical taxonomy [29]. In recent studies different approaches to species recognition generated similar results [30], which suggested that integration of traditional and molecular approaches to species recognition is possible [31]. More recently Identification of Onchocerca spp using cox1 as a molecular marker is considered accurate as previously indicated for Onchocerca spp [32], as well as other filarial species [29]. DNA analysis was considered a good and reliable approach for taxonomical identification of filarioid nematodes, with a high coherence with classical taxonomy [29].

In the present study, the filarial parasite was identified as 0 . flexuosa based on traditional and molecular analysis. Phylogenetic analysis based on cox1, ITS2-28S rRNA, and NAD2 gene sequences revealed that only three main groupings were recorded in the family Onchocercidae, viz., Onchocerca spp, Dirofilaria spp, and Brugia + Wuchereria. Similar conclusion has been reached by $[16,33]$ based upon molecular characteristics and phylogeny of the Filarioidea superfamily. Thus, the phylogenetic aspects of filarial worms may be resolved by analysis based on cox1, ITS2-28S rRNA, and NAD2 genes.

In our opinion, the light of the present work suggests that cox1, ITS2-28S rRNA, and NAD2 appeared an appropriate molecular marker for identification of filarioid nematodes up to species level. Similar suggestion has been reached by using cox 1 and $12 S$ rDNA genes for identification of filarial nematodes up to species level [29]. The phylogenetic analyses of cox1, the ITS2-28S rRNA, and NAD2 genes in that study indicated that $O$. flexuosa isolated from Japanese Sika deer was identical to Onchocerca spp in terms of nucleotide sequences. According to [29], no overlap of intra- and interspecific nucleotide divergence at the cox 1 gene occurs at distance values greater than threshold values (approximately $4.8 \%$ ). Based upon intra- and interspecific nucleotide divergences, in this study we calculated the genetic distance between cox 1 from two different species, and it was greater than the threshold value of $4.8 \%$. Therefore, our findings clearly document the conclusion that the present isolate is $O$. flexuosa, which is distinguished from $O$. dewittei japonica, $O$. takaokai and other congeneric species at the species level, and has a close affinity to other $O$. flexuosa previously reported.

The sequencing analysis is of great importance to identify the origin of the genus Onchocerca and its relation with other members of the family and this characteristic could be used to medicinally control the infection by targeting a specific gene. The emergence of more infectious diseases is a significant problem for the world economy and public health. Majority of these diseases originate in wildlife and spread to other species including animals and humans, and their incidence has increased significantly over the past few decades [34]. Thus, disease surveillance efforts and accurate diagnosis should be applied frequently especially in wildlife to control spread of these pathogens to human or other species.

\section{Declarations}




\section{DISCLOSURE STATEMENT}

No potential conflict of interest was reported by the authors.

\section{References}

1. Deplazes P, Eckert J, Zahner H (2012) Lehrbuch der Parasitologie für die Tiermedizin: Georg Thieme Verlag.

2. Otranto D, Dantas-Torres F., al. CZe (2012) Human ocular filariasis: Further evidence on the zoonotic role of Onchocerca lupi. . Parasit Vectors 5: 84-90.

3. Anderson RC (2000) Nematode parasites of vertebrates: their development and transmission: Cabi.

4. Koehsler M, Soleiman A, Aspöck H, Auer H, Walochnik J (2007) Onchocerca jakutensis filariasis in humans. Emerging infectious diseases 13: 1749.

5. Uni S, Boda T, Daisaku K, Ikura Y, Maruyama H, et al. (2010) Zoonotic filariasis caused by Onchocerca dewittei japonica in a resident of Hiroshima Prefecture, Honshu, Japan. Parasitology international 59: 477-480.

6. Uni S, Fukuda M, Otsuka Yea (2015) New zoonotic cases of Onchocerca dewittei japonica (Nematoda: Onchocercidae) in Honshu, Japan. . Parasit Vectors 8: 59.

7. Bain O, Schulz-Key H (1974) The species of Onchocerca in the red deer: redescription of O. flexuosa (Wedl, 1856) and description of O. tubingensis n. sp. and O. tarsicola n. sp (author's transl). Tropenmedizin und Parasitologie 25: 437-449.

8. Hidalgo M, Martínez A, Carreno R, González S, Ferreras M, et al. (2015) Levels of infection, pathology and nodule size of Onchocerca flexuosa (Nematoda: Onchocercidae) in red deer (Cervus elaphus) from northern Spain. Journal of helminthology 89: 326-334.

9. Bain O (2002) Evolutionary relationships among filarial nematodes. in: Chabaud, A.G., Bain, O., 1976. La ligne'e Dipetalonema. Nouvel essai de classification. Ann Parasitol Hum Comp 51, 365-397.

10. Floyd R, Abebe E, Papert A, Blaxter M (2002) Molecular barcodes for soil nematode identification. Molecular ecology 11: 839-850.

11. Markmann M, Tautz D (2005) Reverse taxonomy: an approach towards determining the diversity of meiobenthic organisms based on ribosomal RNA signature sequences. Philosophical Transactions of the Royal Society of London B: Biological Sciences 360: 1917-1924.

12. Monaghan MT, Balke M, Gregory TR, Vogler AP (2005) DNA-based species delineation in tropical beetles using mitochondrial and nuclear markers. Philosophical Transactions of the Royal Society of London B: Biological Sciences 360: 1925-1933.

13. Anderson RC, Chabaud AG, Willmott S (2009) Keys to the nematode parasites of vertebrates: archival volume: $\mathrm{CABI}$.

14. Uni S, Bain O, Takaoka H, Katsumi A, Fujita H, et al. (2002) Diversification of Cercopithifilaria species (Nematoda: Filarioidea) in Japanese wild ruminants with description of two new species. Parasite- 
Paris 9: 293-304.

15. Yatawara L, Wickramasinghe S, Rajapakse R, Agatsuma T (2010) The complete mitochondrial genome of Setaria digitata (Nematoda: Filarioidea): Mitochondrial gene content, arrangement and composition compared with other nematodes. Molecular and biochemical parasitology 173: 32-38.

16. Yatawara L, Wickramasinghe S, Nagataki M, Rajapakse R, Agatsuma T (2007) Molecular characterization and phylogenetic analysis of Setaria digitata of Sri Lanka based on CO1 and 12S rDNA genes. Veterinary parasitology 148: 161-165.

17. Abd-Ellatieff HA, Abou Rawash AA, Ellakany HF, Goda WM, Suzuki T, et al. (2018) Molecular characterization and phylogenetic analysis of a virulent Marek's disease virus field strain in broiler chickens in Japan. Avian Pathology 47: 47-57.

18. Saitou N, Nei M (1987) The neighbor-joining method: a new method for reconstructing phylogenetic trees. Molecular biology and evolution 4: 406-425.

19. Krueger A, Fischer P, Morales-Hojas R (2007) Molecular phylogeny of the filaria genus Onchocerca with special emphasis on Afrotropical human and bovine parasites. Acta tropica 101: 1-14.

20. Bosch F, Manzanell R, Mathis A (2016) First description of Onchocerca jakutensis (Nematoda: Filarioidea) in red deer (Cervus elaphus) in Switzerland. International Journal for Parasitology: Parasites and Wildlife 5: 192-197.

21. Beaver P, Yoshimura H, Takayasu S, Hashimoto H, Little M (1989) Zoonotic onchocerca in a Japanese child. The American journal of tropical medicine and hygiene 40, 298-300.

22. Bain $O$ (1981) Le genre Onchocerca: hypothèses sur son évolution et clé dichotomique des espèces. Annales de Parasitologie Humaine et Comparée 56: 503-526.

23. Hidalgo-Argüello M, Díez-Baños N, Martínez-Delgado A (2010) Parasitic infections in red deer and their repercusions on animal and human health: a study in the North of the province of León. Parasitic Diseases of Wild Animals and Sustainable Environment The Wild/domestic Interface Universidad Complutense de Madrid, Área de Ciencias de la Salud: 63-95.

24. Suzuki Y, UNI S, KOMATSU T, YAMAMOTO Y, ATOJI Y (1997) Olecranon lesions caused by Onchocerca skrjabini in wild Japanese serows (Capricornis crispus). Journal of veterinary medical science 59: 387-390.

25. Franz M, Schulz-Key, H. \& Copeman, D.B. (1987.) Electron-microscopic observations on the female worms of six Onchocerca species from cattle and red deer. . Parasitology Research 74, 73-83.

26. Plenge-Bo"nig A, Kro“mer, M.\&Bu“ ttner, D.W. (1995.) Light and electronmicroscopy studies onOnchocerca jakutensis and 0 . flexuosa of red deer show different host-parasite interactions. . Parasitology Research 81, 66-73.

27. Yamaguti S (1963) Systema Helminthum. The Nematodes of Vertebrates. Interscience Publ. Inc, New York.

28. Anderson RC, Bain O (1976) Keys to genera of the order Spirurida.Part 3. Diplotriaenoidea, Aproctoidea and Filarioidea. In: Anderson, R.C., Chabaud, A.G., Willmott, S. (Eds.), . ClH Keys to the 
Nematode Parasites of Vertebrates vol. 3. Commonwealth Agricultural Bureaux, Farnham Royal, pp. 59-116.

29. Ferri E, Barbuto M, Bain O, Galimberti A, Uni S, et al. (2009) Integrated taxonomy: traditional approach and DNA barcoding for the identification of filarioid worms and related parasites (Nematoda). Frontiers in zoology 6: 1.

30. Miller SE (2007) DNA barcoding and the renaissance of taxonomy. Proceedings of the National Academy of Sciences 104: 4775-4776.

31. Dettman JR, Jacobson DJ, Turner E, Pringle A, Taylor JW (2003) Reproductive isolation and phylogenetic divergence in Neurospora: comparing methods of species recognition in a model eukaryote. Evolution 57: 2721-2741.

32. Lefoulon E, Giannelli A, Makepeace BL, Mutafchiev Y, Townson S, et al. (2017) Whence river blindness? The domestication of mammals and host-parasite co-evolution in the nematode genus Onchocerca. International journal for parasitology 47: 457-470.

33. Huang H, Wang T, Yang G, Zhang Z, Wang C, et al. (2009) Molecular characterization and phylogenetic analysis of Dirofilaria immitis of China based on COI and 12S rDNA genes. Veterinary parasitology 160: 175-179.

34. Jones KE, Patel NG, Levy MA, Storeygard A, Balk D, et al. (2008) Global trends in emerging infectious diseases. Nature 451: 990.

\section{Tables}

Table 1

History of collected samples from infected deers with O. flexuosa in Gifu and Hino-Shiga Prefectures/Japan.

\begin{tabular}{|c|c|c|c|c|c|c|c|}
\hline \multirow{2}{*}{$\begin{array}{l}\text { Place of } \\
\text { sampling }\end{array}$} & \multicolumn{2}{|c|}{ Host age } & \multicolumn{2}{|l|}{ Sex } & \multirow[t]{2}{*}{ Date } & \multirow[t]{2}{*}{ Habitat in body skin } & \multirow[t]{2}{*}{ Total } \\
\hline & $\begin{array}{l}\leq 2 \\
\text { years }\end{array}$ & $\begin{array}{l}\bigotimes 2 \\
\text { years }\end{array}$ & Male & Female & & & \\
\hline $\begin{array}{l}\text { Gifu } \\
\text { Prefecture }\end{array}$ & 20 & 18 & 13 & 25 & $\begin{array}{l}2016- \\
2018\end{array}$ & $\begin{array}{l}\text { Femur/Abdomen/Back/femur } \\
\text { / All the body skin }\end{array}$ & 77 \\
\hline $\begin{array}{l}\text { Hino-Shiga } \\
\text { Prefecture }\end{array}$ & 17 & 22 & 16 & 23 & $\begin{array}{l}2016- \\
2018\end{array}$ & $\begin{array}{l}\text { Back/ Shoulders/ Femur/ } \\
\text { neck skin }\end{array}$ & \\
\hline
\end{tabular}


Table 2

Sequences of Onchocerca nematode reference strains published in GenBank used for (ITS2 28S rRNA, NAD2, C01) genes.

\begin{tabular}{|c|c|c|}
\hline Onchocerca Strain & Gene Bank Accession number & Origin \\
\hline Onchocercaflexuosa & LC321994(I),LC318284(C01) LC320669 (NAD2) & Japan \\
\hline O. gibsoni isolate Ogib2c4 & DQ317647(I) & Portugal \\
\hline O. gibsoni isolate Ogib2c5 & DQ317648(I) & Portugal \\
\hline O. ochenginsolate 0 och $3 \mathrm{c} 2$ & DQ317659(I) & Portugal \\
\hline O. ochengi & FM206482(I) & Cameroon \\
\hline O. ochengiisolate Ooch3c2 & DQ317661(I) & Portugal \\
\hline O. volvulus isolate Ovol9c3 & DQ317664(I) & Portugal \\
\hline O. volvulus isolate Ovol9c1 & DQ317662(I) & Portugal \\
\hline O. volvulus isolate Ovol9c4 & DQ317665(I) & Portugal \\
\hline O. volvulus isolate Ovol9c2 & DQ317663(I) & Portugal \\
\hline O. gutturosa isolate Ogut2c5 & DQ317653(I) & Portugal \\
\hline O. gutturosa isolate Ogut2c4 & DQ317652(I) & Portugal \\
\hline O. linealis isolate Olien $1 \mathrm{c} 5$ & DQ317657(I) & Portugal \\
\hline O. volvulus & AF015193 (NAD2, C01) & USA \\
\hline Dirofilariaimmitis & AJ537512 (NAD2) & Australia:Victoria \\
\hline Onchocercaflexuosa & AP017692(NAD2, CO1) & Miyazaki \\
\hline Onchocercaochengi & AP017693(NAD2, CO1) & Miyazaki \\
\hline Onchocercaochengi & AP017694(NAD2, CO1) & Miyazaki \\
\hline Onchocerca volvulus & AP017695(NAD2, CO1) & Miyazaki \\
\hline Loa loa & HQ186250 (NAD2) & USA \\
\hline Onchocercaflexuosa & HQ214004 (NAD2, C01) & USA \\
\hline Dirofilariarepens & KR071802 (NAD2, CO1) & Germany \\
\hline Onchocercavolvulus & KT599912 (NAD2, CO1) & Brazil \\
\hline Onchocercaochengi isolate 1 & KX181289 (NAD2, CO1) & Cameroon \\
\hline Onchocercaochengi isolate 2 & KX181290 (NAD2, CO1) & Cameroon \\
\hline Dirofilariarepens & KX265047 (NAD2, CO1) & Italy \\
\hline
\end{tabular}




\begin{tabular}{|c|c|c|}
\hline Onchocerca Strain & Gene Bank Accession number & Origin \\
\hline Dirofilariarepens voucher AW. & KX265048 (NAD2, C01) & Italy \\
\hline Dirofilariarepens voucher S8 & KX265049 (NAD2, CO1) & Croatia \\
\hline Dirofilaria sp. 'hongkongensis' & KX265050 (NAD2) & India \\
\hline Wuchereriabancrofti. & AP017705 (C01) & Miyazaki \\
\hline Wuchereriabancrofti & JN367461 (C01) & USA \\
\hline Wuchereriabancrofti & HQ184469 (CO1) & USA \\
\hline Brugiatimori & AP017686 (C01) & Miyazaki \\
\hline Brugiamalayi & AF538716 (CO1) & UK \\
\hline Brugiapahangi & AP017680 (C01) & Miyazaki \\
\hline \multicolumn{3}{|c|}{$\begin{array}{l}(\mathrm{I})=\text { accession number of internal transcribed spacer subunit } 2(\text { ITS } 2)-28 \text { S ribosomal RNA (28S } \\
\text { rRNA); (COI) = accession number of cytochrome C oxidase subunit } 1(\text { COI); (NAD2) = accession } \\
\text { number of NADH dehydrogenase subunit } 2 \text { gene. }\end{array}$} \\
\hline
\end{tabular}


Table 3

showing the Identity \% and P-distance between the COX1 sequence of isolated strain ( O._flexuosa, \#LC318284.1) and the available sequence of onchocerca species

\begin{tabular}{|lll|}
\hline O._flexuosa_LC318284.1_COX1 & Identity \% & P-Distance \\
\hline O._flexuosa_LC318284.1_COX1 & 100 & \\
\hline O_.flexuosa_AP017692.1 & 93.959 & 0.014 \\
\hline O._flexuosa_HQ214004.1 & 93.635 & 0.018 \\
\hline O._skrjabini :AM749269.1 & 91.776 & 0.038 \\
\hline O._skrjabini :AM749270.1 & 91.776 & 0.038 \\
\hline O._dewittei_japonica:AB518692.1 & 89.676 & 0.047 \\
\hline O._dewittei_japonica_AB518691.1 & 89.368 & 0.048 \\
\hline O._dewittei_japonica:_AB518873.1 & 89.522 & 0.047 \\
\hline O._takaokai: AB972359.1 & 89.68 & 0.045 \\
\hline O._takaokai: AB972360.1 & 89.68 & 0.045 \\
\hline O._sp._wild_boar_AB518693.1 & 89.368 & 0.045 \\
\hline O._volvulus_KT599912.1 & 90.334 & 0.046 \\
\hline O._volvulus_AF015193.1 & 90.308 & 0.045 \\
\hline O._volvulus_:KC167355.1 & 89.985 & 0.045 \\
\hline O._volvulus_AP017695.1 & 90.308 & 0.046 \\
\hline O._ochengi_NC_031891.2 & 89.966 & 0.048 \\
\hline O._ochengi_KX181289.2 & 89.966 & 0.048 \\
\hline O._ochengi_AP017694.1 & 89.852 & 0.049 \\
\hline O._ochengi_AP017693.1 & 89.966 & 0.048 \\
\hline O._ochengi_KX181290.2 & 89.738 & 0.051 \\
\hline O._ochengi:_KP760202.1 & 90.159 & 0.048 \\
\hline O._ochengi_KC167358.1 & 89.831 & 0.048 \\
\hline O._ochengi_KC167350.1 & 89.831 & 0.048 \\
\hline O._ochengi_KC167351.1 & 89.676 & 0.048 \\
\hline O._gutturosa_AJ271617.1 & 90.836 & 0.044 \\
\hline O._gutturosa_KP760201.1 & 90.348 & 0.044 \\
\hline
\end{tabular}




\begin{tabular}{|lll|}
\hline O._flexuosa_LC318284.1_COX1 & Identity \% & P-Distance \\
\hline O._jakutensis_KT001213.1 & 89.318 & 0.045 \\
\hline O._suzukii:_KX853333.1 & 91.429 & 0.050 \\
\hline O._fasciata_JQ316672.1 & 90.28 & 0.047 \\
\hline O._fasciata_MG188678.1 & 90.04 & 0.048 \\
\hline O._lienalis_voucher_KX853326.1 & 91.905 & 0.039 \\
\hline O._lienalis_voucher_KX853325.1 & 89.873 & 0.037 \\
\hline O._lupi_KX132091.1 & 89.953 & 0.045 \\
\hline O._lupi_JX183106.1 & 89.401 & 0.047 \\
\hline O._lupi_HQ207644.1 & 89.522 & 0.046 \\
\hline O._sp._KC167354.1 & 89.522 & 0.051 \\
\hline O._sp._KC167352.1 & 89.676 & 0.050 \\
\hline O._sp._KC167353.1 & 89.676 & 0.050 \\
\hline
\end{tabular}


Table 4

showing the Identity \% and P-distance between the ITS2_28S sequence of isolated strain (0. flexuosaLC321994.1) and the available sequence of onchocerca species

\begin{tabular}{|c|c|c|}
\hline O._flexuosa: LC321994.1 (ITS2_28S gene) & $\begin{array}{l}\text { Identity } \\
\%\end{array}$ & $\begin{array}{l}\text { P- } \\
\text { Distance }\end{array}$ \\
\hline O._flexuosa:LC321994.1 & 100 & 0.000 \\
\hline O._gibsoni:DQ317647.1 & 84.81 & 0.067 \\
\hline O._ochengi:DQ317659.1 & 84.304 & 0.074 \\
\hline O._ochengi:FM206482.1 & 84.051 & 0.067 \\
\hline O._fasciata:JQ316671.1 & 83.291 & 0.046 \\
\hline O._volvulus:DQ317664.1 & 84.091 & 0.074 \\
\hline O._ochengi:DQ317660.1 & 83.333 & 0.074 \\
\hline O._volvulus:AF228572.1, AF228567.1, AF228569.1 & 84.091 & 0.074 \\
\hline O._volvulus:AF228566.1 & 83.838 & 0.074 \\
\hline O._gutturosa:DQ317652.1 & 83.586 & 0.046 \\
\hline O._gibsoni:DQ317646.1, DQ317641.1 & 82.785 & 0.067 \\
\hline O._gibsoni:DQ317644.1 & 82.576 & 0.067 \\
\hline O._gibsoni:DQ317640.1 & 82.532 & 0.067 \\
\hline O._gutturosa:DQ317651.1 & 82.785 & 0.039 \\
\hline O._sp. 1_WS-2017 :MG192127.1 & 85.526 & 0.039 \\
\hline O._gutturosa:DQ317650.1 & 80.759 & 0.046 \\
\hline O._ochengi:DQ317661.1 & 83.333 & 0.074 \\
\hline O._ochengi:DQ317658.1 & 82.828 & 0.060 \\
\hline O._gutturosa: DQ317649.1 & 81.538 & 0.046 \\
\hline $\begin{array}{l}\text { O._dewittei_dewittei: MG192132.1, MG192131.1, MG192130.1, MG192129.1, } \\
\text { MG192128.1, MG192133.1 }\end{array}$ & 83.013 & 0.097 \\
\hline O._dewittei_japonica:MG192134.1_ & 84.722 & 0.074 \\
\hline O._sp._1_WS-2017 :MG192126.1 & 85.197 & 0.060 \\
\hline O._sp._1_WS-2017 :MG192125.1_ & 85.197 & 0.067 \\
\hline O._linealis:DQ317655.1_ & 76.336 & 0.074 \\
\hline O._linealis:DQ317654.1_ & 76.081 & 0.074 \\
\hline
\end{tabular}




\begin{tabular}{|lll|}
\hline O._flexuosa: LC321994.1 (ITS2_28S gene) & $\begin{array}{l}\text { Identity } \\
\%\end{array}$ & $\begin{array}{l}\text { P- } \\
\text { Distance }\end{array}$ \\
\hline D._repens:AY693808.1 & 68.646 & 0.171 \\
\hline D._repens:JQ039744.1 & 68.585 & 0.187 \\
\hline D._repens:JQ039743.1 & 69.83 & 0.187 \\
\hline D._immitis:EU182330.1 & 66.75 & 0.172 \\
\hline D._immitis :EU087699.1_ & 67.866 & 0.163 \\
\hline O._linealis:DQ317656.1 & 76.031 & 0.074 \\
\hline O._linealis:DQ317657.1 & 76.081 & 0.074 \\
\hline
\end{tabular}


Table 5

showing the Identity \% and P-distance between the NAD2 sequence of isolated strain (0. flexuosa LC320669.1) and the available sequence of onchocerca species

\begin{tabular}{|lll|}
\hline O._flexuosa_LC320669.1_NAD2 & Identity \% & P-Distance \\
\hline O._flexuosa_LC320669.1 & 100 & \\
\hline O._flexuosa AP017692.1_ & 90.811 & 0.107 \\
\hline O._flexuosa HQ214004.1 & 90.45 & 0.113 \\
\hline O._volvulus AF015193.1 & 86.876 & 0.167 \\
\hline O._volvulus AP017695.1 & 86.691 & 0.170 \\
\hline O._volvulus KT599912.1 & 86.691 & 0.170 \\
\hline O._ochengi KX181290.2 & 85.661 & 0.185 \\
\hline O._ochengi AP017693.1_ & 86.406 & 0.172 \\
\hline O._ochengi AP017694.1 & 86.406 & 0.172 \\
\hline O._ochengi NC_031891.2 & 86.406 & 0.172 \\
\hline O._ochengi KX181289.2 & 86.406 & 0.172 \\
\hline D._sp._hongkong. KX265050.1 & 86.1 & 0.202 \\
\hline D._immitis AJ537512.1_ & 83.012 & 0.293 \\
\hline Loa_loa HQ186250.1_ & 83.721 & 0.273 \\
\hline D._repens KX265047.1_ & 87.259 & 0.176 \\
\hline D._repens KR071802.1_ & 87.259 & 0.176 \\
\hline D._repens KX265049.1 & 87.066 & 0.180 \\
\hline D._repens KX265048.1_ & 87.452 & 0.172 \\
\hline S._digitata KY284626.1_ & 82.171 & 0.374 \\
\hline S._digitata GU138699.1 & 81.977 & 0.394 \\
\hline A._viteae AP017679.1_ & 82.659 & 0.354 \\
\hline A._viteae HQ186249.1_ & 82.659 & 0.354 \\
\hline W._bancrofti JF775522.1_ & 82.398 & 0.359 \\
\hline W._bancrofti AP017705.1_ & 82.398 & 0.359 \\
\hline W._bancrofti JN367461.1_ & 82.205 & 0.364 \\
\hline W._bancrofti JQ316200.1_ & 82.012 & 0.377 \\
\hline
\end{tabular}




\begin{tabular}{|lll|}
\hline O._flexuosa_LC320669.1_NAD2 & Identity \% & P-Distance \\
\hline W._bancrofti HQ184469.1_ & 82.205 & 0.364 \\
\hline B._pahangi AP017680.1_ & 81.783 & 0.343 \\
\hline B._timori AP017686.1 & 81.008 & 0.370 \\
\hline
\end{tabular}

\section{Supplementary Materials}

Supplemental Tables 1,2 and 3 are not available with this version.

\section{Figures}
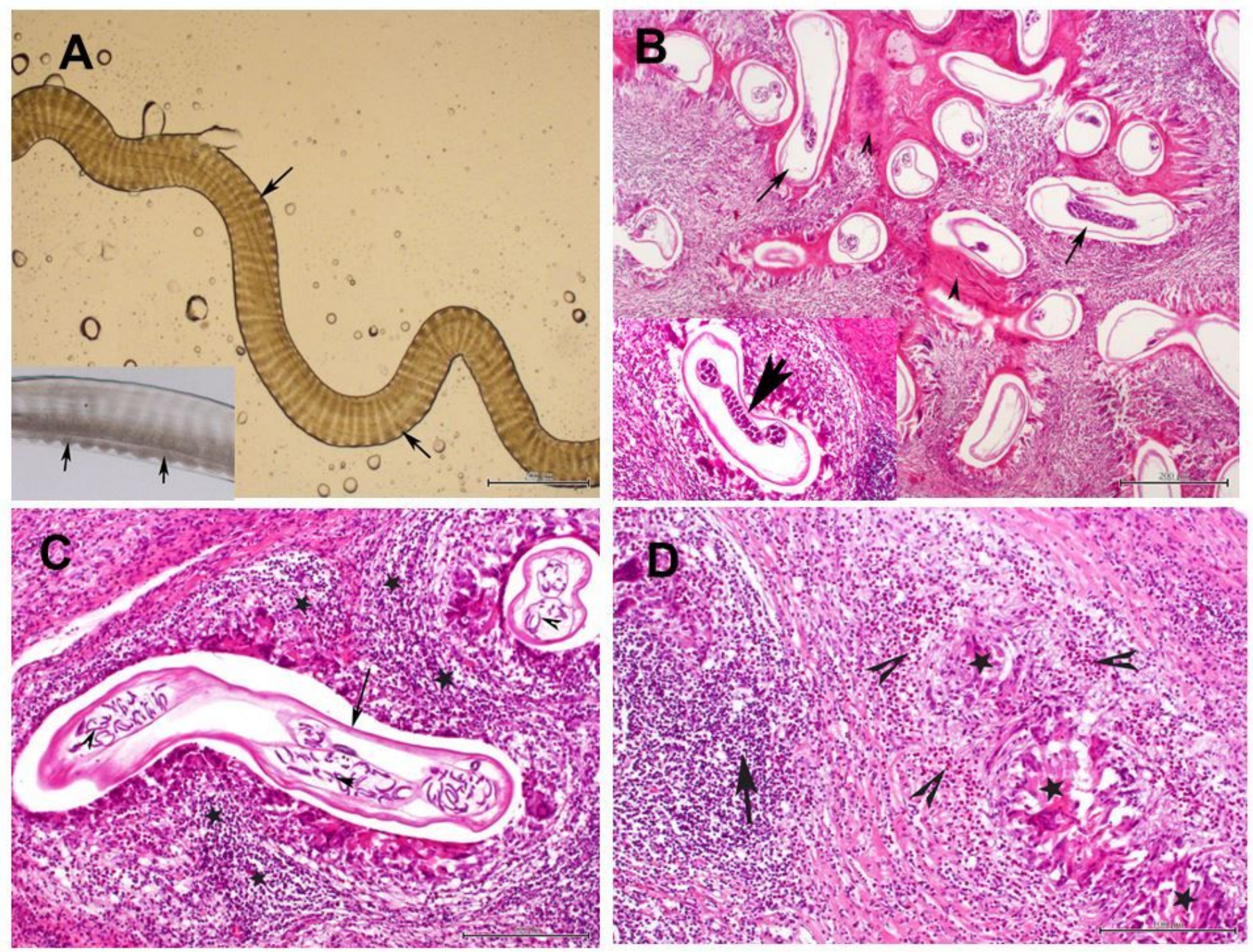

Figure 1 
(A) A fragment of the worm dissected out of the nodule showing marked and straight transverse ridges on the outer surface of the cuticle with small protuberances on the both lateral sides (arrow), Bar = $100 \mu \mathrm{m}$. Inset picture, showing the ridges (arrow), Bar $=20 \mu \mathrm{m}$. (B) Histological section of the subcutaneous nodule showing multiple adult female worms of 0 . flexuosa (arrows) with few males, the parasites are surrounded by homogenous eosinophilic material; inset picture showing the engorged uterus with the parasite, H\&E, Bar $=200 \mu \mathrm{m}$. (C) Onchocerca females (arrow) with numerous microfilariae in the uterus (arrow heads) and granulomatous reaction surrounding the parasite (star) by H\&E staining. Bar $=100 \mu \mathrm{m}$. (D) Degenerated filarial parasites represented by homogenous eosinophilic material (star) and severe granulomatous reaction (arrow) of macrophages and lymphocytes and eosinophilia (arrowheads) by H\&E staining. Bar $=100 \mu \mathrm{m}$.

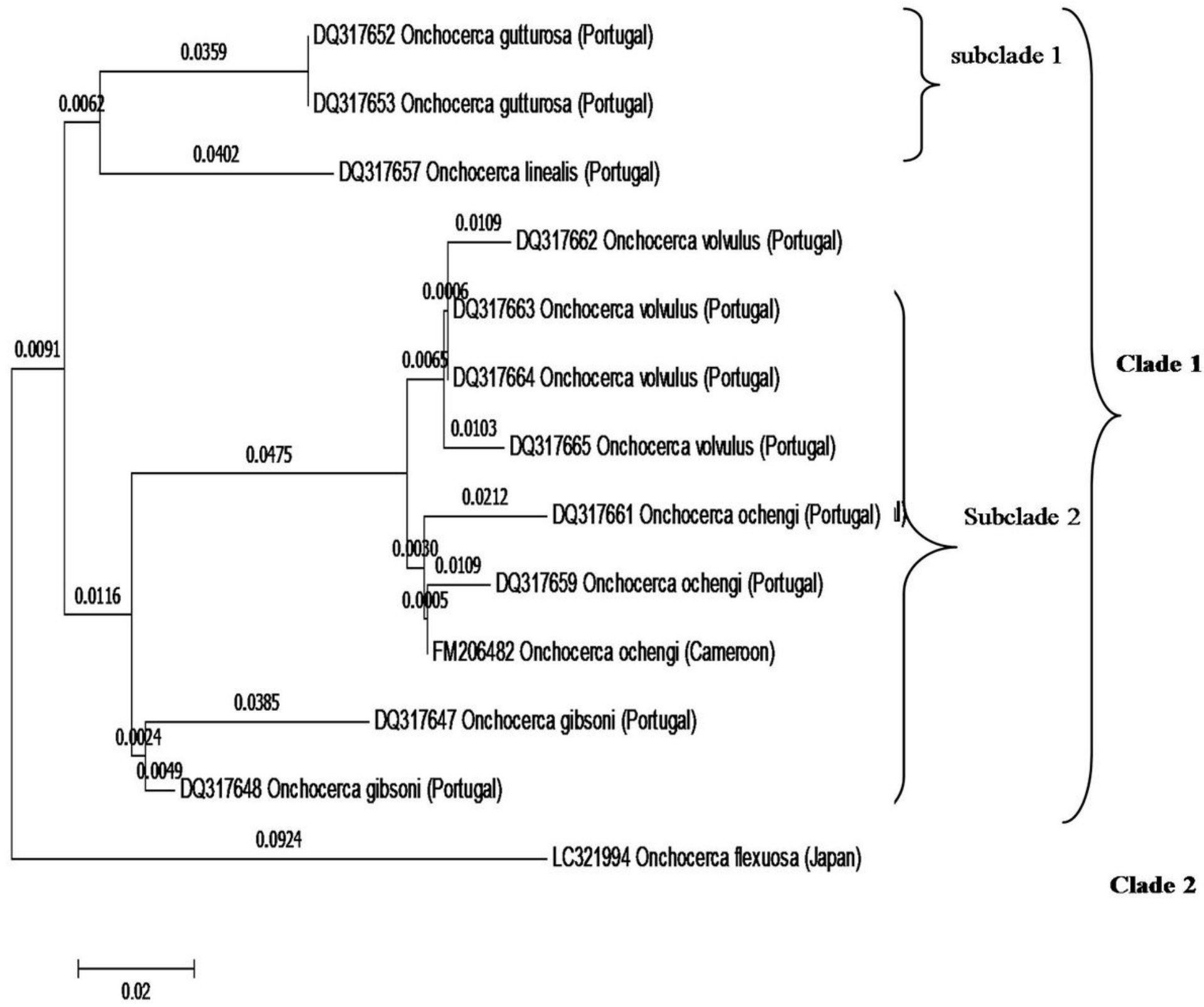

Figure 2 
Phylogeny of Onchocerca spp based on GenBank sequences of the cox1. There were a total of 576 positions in the final dataset. Notice: the present isolate, 0 . flexuosa, formed a monophyletic subgroup sharing the same subclade with 0 . flexuosa isolated from Miyazaki Prefecture and USA, which appeared as sisters in the same branch.

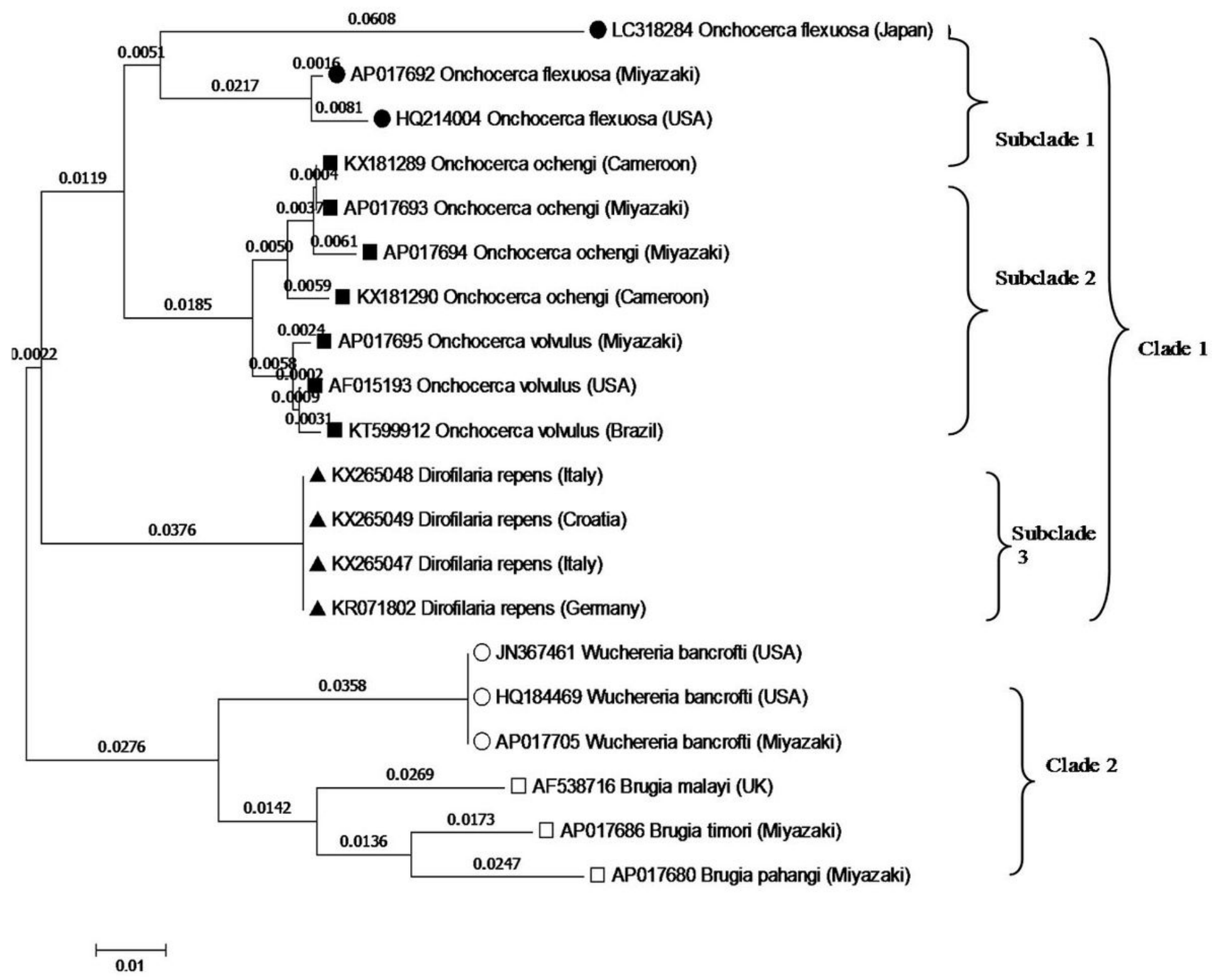

\section{Figure 3}

Phylogeny of filariae and related nematodes based on ITS2 taxa. The GenBank accession numbers for each sequence are shown adjacent to each strain. 


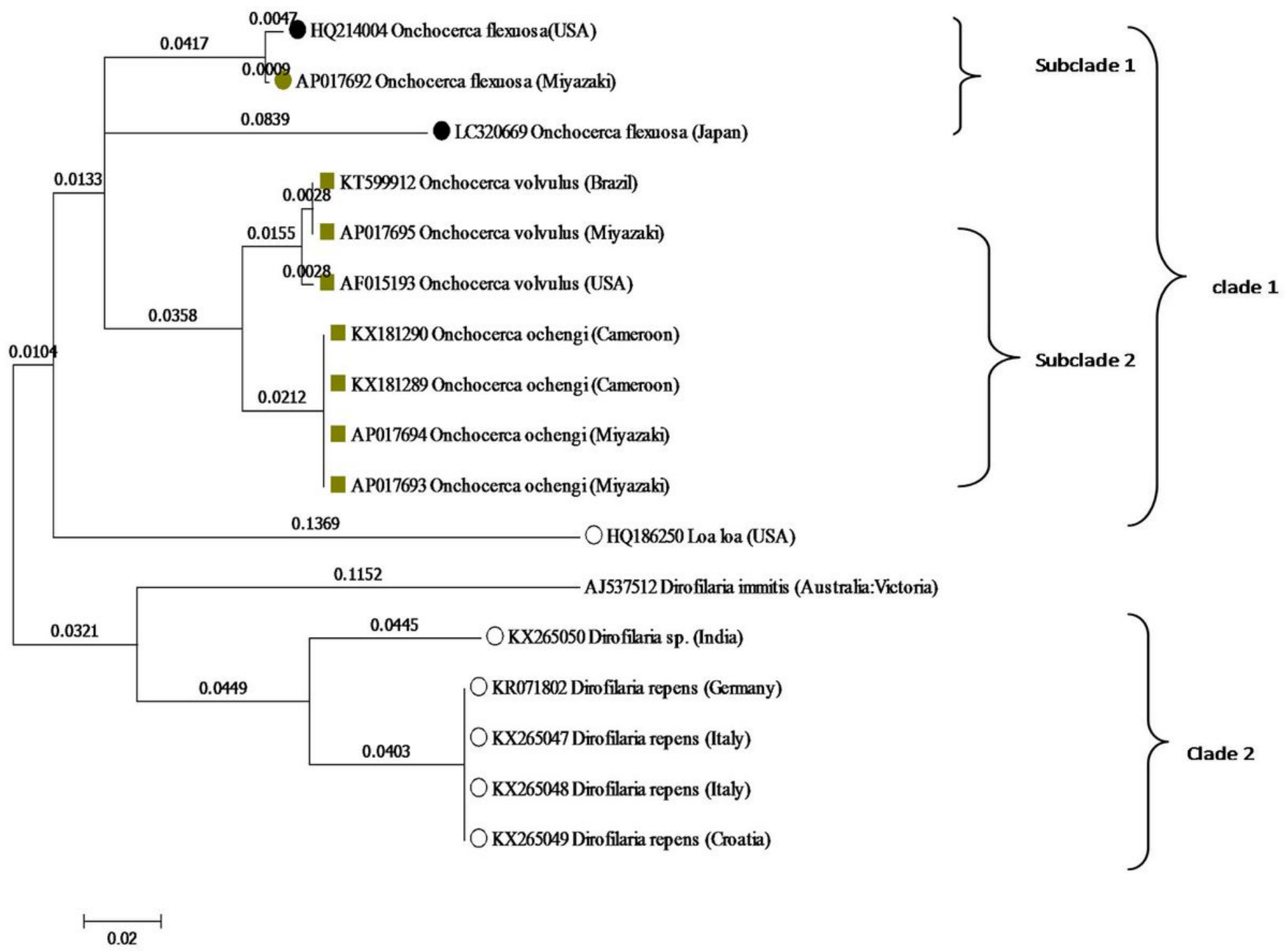

\section{Figure 4}

Evolutionary relationships of NAD2 taxa. The analysis involved 30 nucleotide sequences. Codon positions included were $1 \mathrm{st}+2 \mathrm{nd}+3 \mathrm{rd}+$ Noncoding.

\section{Supplementary Files}

This is a list of supplementary files associated with this preprint. Click to download.

- SupplementaryFigure1.tif

- SupplementaryFigure2.jpg

- SupplementaryFigure3.jpg

- SupplementaryFigure4.jpg 